\title{
Perceptions of rebates for nanny care: An analysis of an online discussion
}

\author{
Susanne Garvis \\ Donna Pendergast
}

Griffith University

CHILDCARE SERVICES IN AUSTRALIA have experienced a rapid growth in demand over the last 30 years. This has paralleled a number of shifts in society, including: the changing roles and expectations of women; the structuring of an economy that relies on dual income as the norm; the assigning of responsibility to the wider community for the adequate provision of child care; and more recently, an expectation that early years child care also performs an educative role. The current Australian context features a mini baby boom (Bryant, 2011) resulting in a strong demand for child care but with an unmatched supply of services. As a potential election promise, the federal opposition leader in 2012 suggested that the Australian childcare rebate for families should be extended to nannies to increase supply and to help with out-of-hours care. This would be a new initiative for the childcare industry. This paper reports on the text analysis of a self-selected group of 113 respondents who posted comments to a website in response to this proposal. Key themes emerged in the posts relating to: the role of women; middle-class welfare; the role of nannies; and the pressures of modern living. Findings from this investigation are important as they provide a moment in time snapshot of perceptions about early childhood education and care. Policy initiatives are explored with a view to address the shortfall in childcare provision; findings are important to provide initial glimpses of community perceptions.

\section{Context}

\section{Changing landscape}

The 1970s and 1980s saw changes to the role of child care in Australian society. During this period, the role of child care in providing 'welfare for children and families in need' faded and it 'increasingly came to be seen as a universal service which facilitated mothers' participation in the workforce' (Katz \& Valentine, 2009, p. 9). In the past few years, rapid change has occurred in early childhood education policy in Australia and in Queensland, where this study was undertaken. The Council of Australian Governments (COAG) noted the importance for all children of having a good start in life and acknowledged that skill development was important from early childhood through to school. A shift in purpose from facilitating workforce participation of carers to improving educational standards thus is driving this agenda.

In December 2009, all Australian governments through COAG agreed to a partnership between the Commonwealth and state and territory governments to establish a National Quality Framework for early childhood education and care
(COAG, 2009). The framework forms part of a broader COAG agenda to pursue substantial reform in the areas of education, skills and early childhood development, to deliver significant improvements in human capital outcomes for all Australians. The framework has also established a new National Quality Standard for early childhood education and care providers in Australia. The National Quality Standard is expected to improve quality through:

improved staff-to-child ratios to ensure each child gets more individual care and attention

new staff qualification requirements to ensure staff have the skills to help children learn and develop

a new quality rating system to ensure Australian families have access to transparent information relating to the quality of early childhood education and care services.

The new improved staff-to-child ratios are presented below in Table 1, for Australian child care provides greater demands on child care for qualified staff. 
Table 1. Ratio of staff to child in child care

\begin{tabular}{|l|c|c|}
\hline Children's age group & $\begin{array}{c}\text { Ratio of } \\
\text { staff to } \\
\text { child }\end{array}$ & $\begin{array}{c}\text { Compliance } \\
\text { date }\end{array}$ \\
\hline Birth-24 months & 1:4 & 1 January 2012 \\
\hline 25-35 months & 1:5 & 1 Jan 2016 \\
\hline 36 months to school age & 1:11 & 1 Jan 2016 \\
\hline
\end{tabular}

In 2009 there were over 871000 children attending an early years service in Australia for an average of 26 hours a week (Australian Bureau of Statistics [ABS], 2010). Children were enrolled in early years services from six weeks of age. In 2009, 530028 children were enrolled in long day care, 106638 in family day care and 8117 were enrolled in limited hours care (ABS, 2010). In 2011, over 800000 children were expected to use government-subsidised child care (Bryant, 2011). The industry is estimated to be worth $\$ 7.8$ billion annually (Bryant, 2011). This has created a significant area of focus for the government in relation to access, cost and quality of early childhood education and care. As more mothers return to the workforce, greater provision for early childhood services has arisen and demand for early child services is expected to grow over the next five years with a mini baby boom (Bryant, 2011).

Yet, regardless of what appears to be a burgeoning industry, parents may find it difficult to find adequate child care to meet their needs in certain locations in Australia. This issue is often reported in the media, where the challenges associated with the provision of child care receive considerable attention in local and national news, including in newspapers. This media focus reflects community interest in the topic, with newsworthy stories important for selling the news to the community. There are many examples of newspaper articles connecting the financial aspects of child care and the ability for mothers to return to the workforce. For example, in 2011 the Sydney Morning Herald published an article entitled Lack of affordable child care keeps 70,000 mothers at home (Burke, 2011). The article reported that women were locked out of the workforce because they could not secure affordable child care. In 2012, the national newspaper The Australian published the article Mums trapped by lack of options (Ley, 2012) in which it was reported that mothers felt that current provisions for child care were inappropriate and out of touch with Australian families. Childcare places were scarce, expensive and did not cater for parents who worked after 6 pm (Ley, 2012). The article highlighted the complex issue of child care in Australia and the lack of services to cater for out-of-hours care. Even though parents have access to a 50 per cent childcare rebate (capped at $\$ 7500$ per annum), there remain problems with demand and supply, both through scarcity and timing of the child care available to working families. The provision of child care to reflect the needs of the community has been such a political issue that in March 2012, the federal political opposition leader Mr Tony Abbott proposed the idea that if his political party were elected to power, he would extend the current childcare rebate to nannies to help ease current problems with the childcare sector. The use of a nanny could alleviate the pressure on out-of-hours care and allow children to remain in their own home. It has the potential to provide parents with the opportunity to match care provision with real working time.

\section{Parent perceptions of early child services}

As yet, few studies have explored parental perception of the quality and utilisation of early childhood in Australia. An analysis of United States research conducted by Rose and Elicker (2008) however reveals that several variables are typically associated with parental childcare decisions, including: cost; income; age of the child (a general preference for parental, in-home, or relative care for infants and toddlers and for centre-based care for older children, possibly because of parental perceptions of differing developmental needs); and maternal characteristics (including educational level, ethnicity, and family role ideology). In their study of 355 employed mothers, Rose and Elicker (2008) further reveal that the most important factors influencing parental decision making about child care, in order of importance, were warmth of caregivers, followed by the presence of a play-based curriculum, and thirdly the educational level of caregivers.

In the most recent study in Queensland in 2010, Weaven and Grace (2011) explored parental perceptions of quality in early years long day care by interviewing parents. Findings suggest parents tend to associate quality with observable childcare experiences such as interactions between child and carer, rather than structured elements, such as staffchild ratios, group size, and caregiver qualifications. The study also revealed that parents viewed independentprivate centres as marginally superior to communitymanaged childcare centres and that parents suggested that private centres also offered the highest levels of care in promoting hygienic and safe learning environments for children; providing nutritious food, and stimulating toys and equipment; developing appropriate developmental activities; and administering group activities. All of these factors contribute to the participation rate, and this is ultimately of interest to those aiming to increase engagement and participation with the services, in order to gain benefits of participation. The study revealed that parents wanted choice in where they could send their children.

\section{Perceptions of nannies in Australia}

According to reporter Symons (2012), the problem of early childhood services can be fixed if we look at how nannies are perceived in other countries. She argued in the Financial Review (2 April 2012) that early childhood education and the professional care of infants adds up to pedagogical and societal market failure: 
[W] hen it comes to early childhood education and the professional care of infants, Australia is, according to study after study, bottom of the rich-world heap. Our pre-school system is a 'glorified playgroup' at best, and we have woefully inadequate quality daycare for children under the age of two. Australia has a nanny problem that is both one of mentality-nannies are for rich, lazy, neglectful mothers-and lack of availability. Anyone who has travelled to or worked in New York, Paris or any Asian capital can tell you why: Australia has a comparatively small supply of reasonably qualified workers prepared to do full-time nannying on wages most middle and upper-income professional couples can afford to pay them.

As yet, there has been limited data that has explored the perceptions of nannies on the Australian landscape for families. This paper contributes in some way to help fill that void.

\section{The study}

In 2012, the article Rebate for nanny care will reduce baby blues (Michael, 2012) appeared on the Sydney Morning Herald website. The article was a critique of federal opposition leader Tony Abbott's suggestion that his political party would consider a nanny rebate if elected to help ease current problems resulting from inadequate numbers of childcare places. Most articles on the Sydney Morning Herald website have an anonymous blog post attached where readers can post their comments. This particular forum recorded 113 posts from anonymous contributors. Comments for the story were open from 27 March 2012, 8:19 am, to 27 March 2012, 4:34 pm, which is a duration of just over eight hours. This study analyses the 113 comments from members of the community that were posted to the online website.

Respondents were a self-selecting, anonymous convenience sample. On average, most contributors wrote three to four sentences. All posts were downloaded and screened for use in this study. All 113 posts were considered suitable for inclusion and they were all either explicitly or implicitly presented as 'parents'. Because of the small number of comments, the narrow time period to post comments and the convenience sampling of respondents, the findings of this study are reported in the context of the sample only, and there is no attempt to extrapolate findings to the wider community.

All comments were subjected to analysis by Lexminacer (Version 3). Leximancer is text analysis software that uses Bayesian algorithms to visually represent the underlying conceptual structure of the text. Leximancer analyses the conditional probability of the relatedness of concepts (represented as dots) and places more closely related concepts closer in proximity than concepts that are distantly related. This is in opposition to other automated text analysis software packages that aim to determine meaning by word count alone. Leximancer aims to determine the underlying meaning of the words by analysing which words (concepts) 'travel' together in the text. Lines connecting concepts are also used to indicate the strength of the relationships between concepts.

Leximancer also interrogates the concepts to identify underlying themes. Our analysis revealed that the comments related to four main areas: definition and role of nannies; the role of women in society; pressures of modern living; and community perception of middle-class welfare. Connectivity is a measure of the salience or strength of the theme and represents the degree to which the concepts within a particular theme are related to other concepts. It is referenced to 100 per cent for the theme with the highest number of responses. The strength of the relationship between the themes is expressed in percentage, with the higher the percentage the greater the connection to the dominant theme.

\section{Findings}

In this study the dominant theme is 'Definition and role of the nanny' theme. This means that there were more comments related to this theme. It is a reference point for the degree of connection between this and the other three themes. Table 2 shows the themes, their connectivity and the concepts identified within each theme. Leximancer generates a theme label based upon the concept with the highest connectivity in each theme. In this study, the initial theme labels were 'nanny', 'tax', and 'people' and 'children'. After a reading of the comments identified by Leximancer as evidence for the themes, the automatically generated theme labels were replaced by the researchers with more descriptive theme headings, these being: 'definition and role of the nanny', 'middle-class welfare', 'pressures of modern living' and 'role of women', respectively, to better reflect the comments within each theme. Each key theme, along with examples of comments, is presented after Table 2.

\section{Table 2. Four key themes and their related concepts}

\begin{tabular}{|l|c|l|}
\hline $\begin{array}{l}\text { Theme } \\
\text { Definition } \\
\text { and role of } \\
\text { the nanny }\end{array}$ & 100 & $\begin{array}{l}\text { Work, pay, child, care, } \\
\text { people, childcare, cost, } \\
\text { centre, support, rebate, } \\
\text { population }\end{array}$ \\
\hline $\begin{array}{l}\text { Pressures } \\
\text { of modern } \\
\text { living }\end{array}$ & 47 & $\begin{array}{l}\text { live, parents, afford, } \\
\text { society }\end{array}$ \\
\hline $\begin{array}{l}\text { Middle-class } \\
\text { welfare }\end{array}$ & 30 & $\begin{array}{l}\text { tax, welfare, } \\
\text { government, class, } \\
\text { middle }\end{array}$ \\
\hline $\begin{array}{l}\text { Role of } \\
\text { women }\end{array}$ & 29 & $\begin{array}{l}\text { home, look, families, } \\
\text { women, career, rich }\end{array}$ \\
\hline
\end{tabular}




\section{Definition of and role of the nanny}

Predictably, given the content of the stimulus news article, the majority of responses were related to understandings of the role of 'nanny' with contributors presenting arguments from their particular conception of 'nanny'. Many of the comments which were negatively disposed to the subsidising of nannies held what could be described as a traditional definition of a nanny, which is an employee, most likely a young female, of a rich family. For example:

... we're talking about nannies. Staff employed by families, and wealthy families at that. (Respondent, James from Brisbane)

The majority of my friends and former colleagues who employ nannies use barely out of school children with no early childhood education qualifications and pay cash in hand at below minimum wage rates ... (Respondent, shaking my head)

Other respondents chose less flattering characterisations of the nanny, equating them with being 'stupid' and relabelled as 'domestic staff', as evident in the following texts:

[T] he problem with nannies is, why can't they get better work? Do you want your child reared by someone who is too stupid to get a better job, what sort of rubbish will they fill your kids' heads full of? (Respondent, baby boomer)

... It would be a good way for well-off families to get a subsidised cleaner. Just rebadge them 'the nanny'. An absurd idea open to all sorts of misuse. (Respondent, in reality)

Having 'nannies' is yet another form of sexism. Is not a nanny female? Low pay, young kids, or career single women looking after other people's children, or women whose children have grown up and looking for extra income when they have no skills? (Respondent, CCB)

Some respondents who appeared to be in favour of the proposed scheme pointed out that nannies were not necessarily employed by 'rich' families but were simply an option selected by a group of working-class families, when child care that would be able to meet their particular needs was not provided, as evident in the following comments:

I hope that employing nannies doesn't fit into your category of middle and upper class welfare? I live in the inner west and there are many of us who don't earn enough on one income so we pool together our monies to employ a nanny to take care of our kids as there are no child care alternatives for children these ages. This way both parents can work to pay for our living expenses and those taxes which keep the government going. This is hardly middle or upper class welfare. (Respondent, Bennopia)
I worked as a nanny in both London and Paris ... It is not always the rich that have nannies-some families were able to pool together and have one nanny look after three children ... (Respondent, MB)

\section{Middle-class welfare}

This theme had a 24 per cent connectivity to the main theme, which means that quite often the postings contained comments about both the definition and role of nanny and how this connected to the idea of middleclass welfare. Sub-themes identified within the larger theme of 'middle-class welfare' in order of salience were: attacks on the perceived welfare mentality; arguments that such a scheme would not be economically viable for the government; and the perception of 'vote buying' by the political party suggesting the scheme.

Many respondents were against the proposed scheme as they identified it as 'middle-class welfare', and that it is not the role of welfare nor the government to support what they perceived to be lifestyle choices made by the potential recipients of the benefit. The issue of having children as a lifestyle choice will be discussed further in the section on 'pressures of modern living'.

I too am happy to pay my taxes for things that benefit all Australians such as roads, defence, pensions, infrastructure etc. What I am not happy to pay taxes for is for subsidised wealth redistribution from singles and childless couples to pay for lifestyle choices. (Respondent, Shane from Melbourne)

Wasting money on welfare is not the answer. Welfare should be used only as an automatic stabiliser. It is not a right nor even is it a privilege. It's a waste. I just wish there was a party that doesn't seem to support the persistent welfare state. (Respondent, Bender)

Other respondents not supportive of the proposed scheme saw this as a cynical move by the proposing political party of vote buying, in particular the targeting of families. The following comments reflected the politicisation of the proposal:

... It's just spin to bolster Abbott's standing with the female voter. (Respondent, Swifty)

Oh well, the Liberal party is buying votes again and I'm going to get a nanny, child benefits and the baby bonus! (Respondent, Anthony)

A third argument against the proposed scheme identified potential problems with funding of the scheme, with respondents labelling it as uneconomical, as evident in the following quotes:

There is a big flaw in logic here. You say the child care system is not working, as the govt is insisting on a 1:4 ratio. Now you pretty much want a govt subsidy to make it 1:1. Where are all these nannies supposed to come from? My guess is that only a small proportion 
could afford it (people who it is out of reach for now, but not by much). While I understand your aims, I just cannot agree with taxpayer funds going to a small number of better-off parents. (Respondent, Lazy guy)

So a nanny subsidy would probably average out to paying one adult's wages for caring for about 1.5 kids (compared to the 1 to 4 ratio in care). (Respondent, Peter)

\section{Pressures of modern living}

Many of the sub-themes within the two remaining themes, 'pressures of modern living' and 'role of women in modern society', were related in some aspect to the two most salient themes of the 'definition and role of the nanny' and the labelling of the proposed measure as 'middle-class welfare'. The theme 'pressure of modern living' had a 47 per cent connectivity to the main theme, which means that quite often the postings contained comments about both the definition and role of 'nanny' and how this connected to the idea of pressures of modern living.

In the theme 'pressures of modern living' the two subthemes that emerged were: having children as a lifestyle choice, and couples living beyond their means. Hence, this theme was very negatively disposed to the idea of nanny funding support as a childcare initiative. Respondents who were in favour of the proposed scheme cited reasons such as the necessity to remain in the workforce in order to maintain their careers.

The majority of responses that could be characterised within the sub-theme of having children as a lifestyle choice identified that in previous decades families made a choice to have children, taking personal financial responsibility for the decision rather than relying upon government assistance. Comments in this sub-theme are closely related to the comments referring to the middleclass welfare mentality of some parents. The following comments are typical of this type of posting:

Pay for your kids yourself. If you can't or don't want to take time off work that is your problem. Sick of whiney Australians sticking their hands out. (Respondent, Tunnels Newman)

You are sorely mistaken if you think your grandparents didn't monitor what they spent when bringing up children. It didn't just 'happen'. They lived within their means. There was a time when a family of four could live in a three-bedroom house with one bathroom and one living room. (Respondent, Bender)

Respondents in favour of the scheme used personal examples to illustrate how they took financial responsibility for their decisions and highlighted the added benefit of remaining within the workforce to allow their careers to advance.
When I returned to work after having two children I employed a full-time nanny because I wanted my children to be in their own home, playing with their own toys and having special care if they were not well. I never expected any government handouts for what was a personal choice on my part. Almost all of my salary went to pay the nanny, which I thought was a fair investment, given that it allowed my career to continue without too long a break. (Respondent, em)

Other respondents in favour of the scheme pointed to their understanding that childcare centres operate on the model that parents work the standard 9 am to $5 \mathrm{pm}$. These respondents saw the nanny initiative as an option for workers who did not work these standard hours, as indicated in the following comments:

We need childcare facilities that are flexible enough to accommodate different working hours ... This is about recognising that there are quite a few of us that have different work schedules from the standard hours, and having equal access to child care ... (Respondent, Queanbeyanite)

Nannies are a good solution for women in well-paid jobs who can't drop their kids off after 8 am and collect them before 6pm. (Respondent, baby boomer)

The reality is daycare doesn't suit all families, as I work by a calendar month; my work days aren't set days of the week and most day care centres can't accommodate changing days. A nanny is a great solution. If society accepts the subsidising of centrebased childcare, why not a nanny? The implication nannies are only for high-income earners is untrue. (Respondent, JJS)

\section{The role of women in modern society}

The theme 'role of women in modern society' had a 29 per cent connectivity to the main theme, which means that quite often the postings contained comments about both the definition and role of nanny and how this connected to the role of women in modern society. Many of the comments within the theme were targeted at the author of the stimulus article, and in particular criticising the line, 'Some social conservatives would say women should really stay at home. Only that's not a solution for anyone in the modern world, except those who are not really part of it anyway-hippies, heiresses, wives of the super rich and the catatonically unambitious.' Some respondents labelled this line as 'offensive', 'insulting' and degrading to women who choose this as an option, as evident in the following comment:

Offensive nonsense. If it suits your selfish worldview to paint stay at home mothers into four narrow boxes, go right ahead. Whatever helps you reconcile your decision to leave your children to be raised by other people. Staying home with your children is a valid 
solution in the 'modern world' if you have a lifestyle that can be comfortably supported on one average income, different families have different priorities and if being with your children is your priority it is certainly possible. (Respondent, Mtns mama)

However, the sentiment of the line in the newspaper article-the traditional roles of men and women-were echoed in some comments, such as the following:

It was never needed as the man would work, the women would look after the children. Nowadays things have changed. (Respondent, Jen)

I'd rather the mother think about the costs of having a child prior to getting pregnant and not expect taxpayer support for what is a very personal decision. (Respondent, Anthony)

\section{Discussion}

The key themes that emerged from this analysis were: the role of women in Australian society; middle-class welfare; the role of nannies; and the pressures of modern living. Connections between the themes were evident.

The 'definition and role of the nanny' presented a snapshot understanding of the conception and characteristics of a nanny. The majority of respondents suggested that a nanny was only for a wealthy family and held limited educational qualifications. Some respondents also reported that nannies were 'stupid' as they could not find employment elsewhere. These comments suggest that the community may have a limited understanding of the role of the nanny, and the diversity in functions such a role may bring.

A small majority of respondents tried to challenge the traditional notions of a nanny. One particular respondent suggested she and others pooled money together for a nanny as there were no alternatives for child care. A nanny also responded saying that in other countries, nannies aren't always for the rich. Rather, some families will hire a nanny between them to allow child care. If this proposal is being considered to contribute to addressing the lack of suitable child care to meet the diverse needs of families, it is important that the community understands the actual role and qualifications of a nanny. It is also important for the community to understand that the option for a nanny allows both parents the opportunity to engage in the workforce to meet everyday expenses.

'Middle-class welfare' also emerged as a theme with arguments put forward that the idea was a 'vote buying' strategy. While respondents were happy for their taxes to be spent towards defence, pensions and infrastructure, they were unhappy for taxes to be spent on the care of young children because it was seen to be the responsibility of the parents to provide care. This suggests that while respondents recognised the importance of welfare for older Australians, they did not see the importance of welfare for young children in Australia. Comments from participants pointed to a limited understanding of the importance of early childhood education and intervention as preventions for later societal issues. The comments also reflect the limited valuing of young children in the Australian society. Participants did not point to the importance of providing young children with a healthy start in life but rather as a further tax burden to society. Increasing birth rates to help sustain the population were not considered to be a responsibility of the government, as reflected in this data set.

'Pressures of modern living' was also reflected as a theme highlighting that current structures of the workplace may not align with early childhood centres and that it was difficult to find care outside the hours of 9 am to $5 \mathrm{pm}$. This presents problems for many families who may engage in shift work or extended hours. Some participants stated that providing financial support to engage a nanny was an appropriate strategy to help ease this problem for some families.

The 'roles of women in modern society' also emerged as a theme. Some of the comments clearly argued that the role of the woman was to stay at home and provide child care. Others argued the counter position, suggesting that women should be allowed to have options in the workforce and hence childcare facilities to support these options. Another strong view was that while women should be allowed to have options to re-engage with the workforce and it was important to contribute to society, children were an individual choice and should be funded solely by parents. For those presenting this position, the care of children in Australian society is argued to be an individual (family) and not a collective concern. From the opinions expressed in the comments, young children do not appear to be an important area for government funding and are considered to be an individual responsibility. As will be discussed, this is not a view shared by the current Labor government on issues of child care.

While the article that stimulated this online discussion discussed nannies, it is interesting to note that three of the emergent themes were raised as issues by the office of Hon Kate Ellis MP, Minister for Employment Participation and Early Childhood and Child Care, who on 17 March 2013, announced flexible childcare options for modern families (Ellis, 2013). The three-point trial aims to provide overnight and weekend care for police, nurses and paramedics who are shift workers, a trial of flexible extended-hours weekday care and more out-of -school-hours care. These initiatives deal directly with the 'pressures on modern families', and the 'role of women in modern society', both themes identified in the analysis. It is also interesting to note that the issue of 'middle-class welfare' was addressed in the press release, '[Abbott] will not rule out cutting the Child Care Rebate, something that is deeply unsettling for working parents who rely on the Rebate to meet their child care costs' (Ellis, 2013, p. 1). It bodes well for this 
methodology of gaining public perceptions on a topic using internet discussion forums when the analysis reveals a high similarity with the issues that ministerial offices try to address in the policy formation.

\section{Conclusion}

This paper reveals the key messages in 113 comments posted to an online site in response to a newspaper article about a possible proposal by a politician to provide childcare rebate for nannies to assist working families in Australia. It has provided a snapshot in time insight into understandings of early childhood services, the role of women, middle-class welfare and the pressures of modern living. As policy initiatives are explored with a view to address the shortfall in childcare provision, it is important that policy-makers are aware of the issues surrounding raising children in Australia and the position from which members of the community respond to such proposals.

\section{References}

Australian Bureau of Statistics. (2010). Childcare. Retrieved 3 April, 2012, from www.abs.gov.au/AUSSTATS/abs@.nsf/Lookup/4102.0 Main+Features50Jun+2010.

Bryant, R. (2011). The childcare industry's growth spurt. Retrieved 3 April, 2012, from www.smartcompany.com.au/professionalservices/baby-steps.html.

Burke, K. (2011). Lack of affordable childcare keeps 70,000 mothers at home. The Sydney Morning Herald. Retreived 2 February, 2013, from www.smh.com.au/lifestyle/life/lack-of-affordable-childcarekeeps-7000-mothers-at-home-20111206-1oh5y.html.

Council of Australian Government. (2009). National Quality Framework for Early Childhood Education and Care. Retrieved 2 March, 2012, from www.deewr.gov.au/earlychildhood/policy agenda/quality/pages/home.aspx

Ellis, K. (2013). Flexible child care options for modern families. Retrieved 2 February, 2013, from http://ministers.deewr.gov.au/ ellis/flexible-child-care-options-modern-families.

Katz, I. \& Valentine, K. (2009). Lessons for Australia from the UK Sure Start Programme, SPRC Report 2/09, report prepared for Department of Families, Housing, Community Services and Indigenous Affairs, submitted July 2006, published April 2009.

Ley, S. (2012). Mums trapped by lack of options. The Australian. Retreived 2 February 2013, from www.theaustralian.com.au/ national-affairs/opinions/mums-trapped-by-lack-of-options/storye6fgdx-1226316043535.

Michael, C. (2012, March 27). Rebate for nanny care will reduce baby blues. Sydney Morning Herald. Retreived 4 December, 2012 from www.smh.com.au/federal-politics/political-opinion/rebate-fornanny-care-will-reduce-baby-blues-20120326-Ivuly.html.

Rose, K. \& Elicker, J. (2008). Parental decision making about child care. Journal of Family Issues, 29(9), 1161-1184.

Symons, E. K. (2012, April 2). Nanny state: Solutions just a visa away. Financial Review. Retreived 2 May, 2012, from www. afr.com/p/opinion/nanny_state_solutions_just_visa_uqDm_ IMYDc1M8X+Zin0ERDN.
Weaven, S., \& Grace, D. (2010). Examining parental and child care staff perceptions of child care service quality across competing business structures. Australasian Journal of Early Childhood, 35(2), 54-62. 